MR. BRANDE ON THE WELL-WATER OF THE ROYAL MINT. 345

\title{
XXXII.-Analysis of the Well-Water at the Royal Mint, with some Remarks on the Waters of the London Wells.
}

\section{By William Thomas Brande, Esq., F.R.S., V.P.C.S. \&c.}

Previous to the year 1842, the Mint was supplied with water principally from two sources: the dwelling-houses, offices, and a part of the works, by the New River Company; and the steam engines, by wells partly supplied by so-called land-springs, and partly by a tunnel communicating with the Tower Moat; the principal supplies being derived from the latter; so that when in consequence of any works carrying on at the Tower, the access of the river to the moat was impeded, the operations of the Mint were not unfrequently obliged to be suspended; besides which, the water derived from that source was always muddy, and often very foul and offensive.

In consequence of this bad condition of the water in the Tower Moat, and the effluvia arising from it in hot weather, it was resolved in the year 1843, to drain and lay it dry. The Mint was accordingly altogether deprived of its supply of water from that source, and the land springs supplying the wells of the several steam engines, to say nothing of the impurity and hardness of the water thence derived, were found wholly inadequate to the wants of the engines. It therefore became necessary to have recourse to the New River Company for such additional supplies of water as might be wanted for carrying on the business of the Mint; and for this, their charges, as far as the steam engines were concerned, were at the rate of $£ 10$ per horse power per annum; but, from various causes, these supplies could not always be depended on, so that on several occasions a temporary suspension of the business of the Mint was the consequence of a deficient supply of water.

Under these circumstances it became my duty to suggest to the Master of the Mint, the adoption of such measures as might ensure for the future a regular and adequate supply of water for the use of the whole establishment, and to this end, it was necessary in the first instance, to make myself accurately acquainted with the actual condition of the several wells existing in the Mint, and with the quantity and quality of the water which might be derived from them. I was therefore authorised by the Master of the Mint to consult with Mr. Thomas Clark, an experienced Well Engineer, in reference to the subject; and I accordingly desired him to examine into the

vol. II.-No. viII.

A A 
condition and capabilities, of all the wells, shafts, and tunnels, connected with the supplies of water throughout the building. This examination was carefully and effectually accomplished; and it appeared that the several wells were in a very dilapidated, and some of them, in a very dangerous state; that few of them were so situated, or conditioned, as to admit of being sufficiently or safely deepened, so as to yield an adequate supply of water; and that, as respected the wells in the several engine-houses, they were mere reservoirs connected with the tunnel-shaft from the Tower, and therefore almost exclusively supplied from the muddy source of the Tower Moat.

Having personally convinced myself of the correctness of this Report, and having had Mr. Clark's statement corroborated by Mr. George Rennie, I represented the matter in detail to the Master of the Mint, and suggested three plans for consideration, namely: 1. To derive the requisite supplies of water from the Water Companies. 2. To repair the present wells, and to deepen such of them as would admit of that operation. 3. To sink an entirely new well : and I strongly urged the adoption of the latter alternative, which, after due consideration, was agreed to. I therefore obtained proper plans and estimates from Mr. Clark, which, after having been submitted to the Board of Woods, and by their direction, to Major Jebb, were ultimately ordered to be carried into execution.

These plans included the sinking of an entirely new well; the erection of a capacious water-tank, at a sufficient height to supply the ordinary demands of the Mint; proper pumps for raising the water, and mains for distributing it over all parts of the buildings; together with fire-cocks, and other arrangements, the details of which would be irrelevant to the object of this communication.

It may be right to premise, that the total depth of this new well is about 426 feet; that the depth from the surface down to the chalk is about 224 feet; and the borings into the chalk about 202 feet; the following being the well-sinkers' account of the strata gone through ; namely :

Gravel and sand (with water).$\quad \cdot \quad \cdot \quad \cdot \quad \cdot \quad \cdot \quad \cdot \quad \cdot \quad \cdot 11$

Blue clay with a few sandy veins (no water) . $\quad$. $\quad$. 98

Coloured sand and pebbles (abundance of water) . . 14

Dark sand with veins of clay (little water) . . . 4 
WELL-WATER OF THE ROYAL MINT.

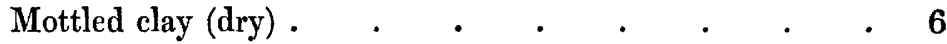

Loamy sand and dark clay (little water) . $\quad$. $\quad$. $\quad$. 5

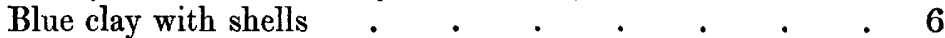

White rock (quite dry)

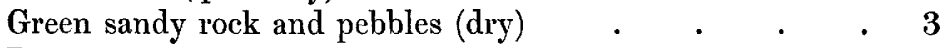

Loamy green sand and black pebbles (little water) . $\quad 5$

Green sand and pebbles (abundance of water) . $\quad$ • $\quad$. 6

Dark sand with shells . . . . . . . . 40

Flints . . . . . . . . . . . 10

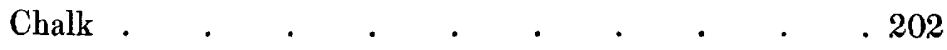

The lining of the upper part of the well, through the gravel and nto the blue clay, is composed of stout cast iron cylinders, $1 \frac{1}{4}$ inch thick, and 8 feet clear diameter; they are made in 5 feet lengths, with internal flanges 3 inches wide, packed, and jointed with strong bolts and nuts : these prevent all access of the land springs from above. The shaft is then steined to the depth of 88 feet, (that is, nearly through the blue clay), in 9-inch cemented brickwork; after which, cast iron cylinders are resumed, of 7 feet diameter, and these are continued down to the chalk; but after passing through the stratum of mottled clay, they include a series of cylinders of 6 feet diameter, the space between the outer and inner cylinders, being filled with gravelpebbles; a bore-pipe, 20 inches diameter and 45 feet long, is then driven to about 10 feet into the chalk, and through this the boring is continued, by an 18-inch auger, to the entire depth of the well.

This well, and all the works connected with it, were completed at Christmas 1846, and on the 1st of January 1847, the whole of the works of the Mint, and the dwelling-houses, were supplied with the water, which is raised in a 6-inch main to a height of 50 feet above the surface, or 130 feet above the average level of the water in the well; and is delivered at the rate of 240 gallons per minute, by means of three pumps of 9-inch diameter and 8-inch stroke, into a tank supported upon a building of brickwork. This tank is 100 feet long, 30 wide, and 5 deep; it contains, therefore, 15,000 cubic feet of water, or 93,750 imperial gallons. Two 6-inch cast-iron mains, furnished with proper slide valves, descend from this tank, one passing on either side of the Mint, so as conveniently to supply the whole of the establishment: the daily consumption of water fre- 
quently exceeding 40,000 gallons; besides which, a daily supply of about 6,000 gallons is delivered, by means of a main laid from the Mint across Tower Hill, to the Tower, for the use of the inhabitants and the garrison; there being at present no serviceable wells in that fortress, and the water derived from the adjacent river being objectionable in point of cleanliness.

The average height which the water attains in the shaft of the Mint well is 80 feet from the surface. After a day's pumping it is lowered, upon an average, 20 feet, but there it remains stationary, the flow of water from below maintaining the level, or in other words, delivering at the rate of about 240 gallons per minute.

Before this well was completed, and before the boring into the chalk had been accomplished, the water derived from it contained 44 grains of dry saline matter in the imperial gallon. At present, the machinery being complete, and the well in full and daily use, the mean of several experiments in reference to the solid matter contained in the imperial gallon of the water, amounts to 37.5 grains.

The substances contained in each gallon of the water are as follow :

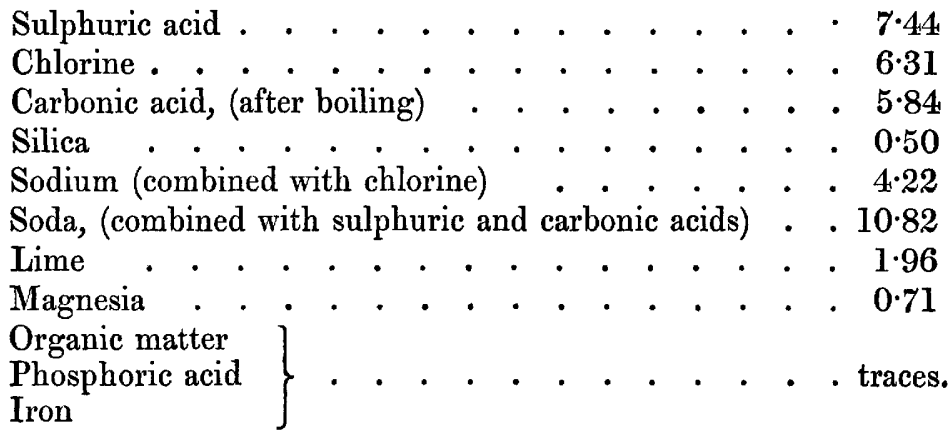

The water evaporated to one-fifth of its bulk, and filtered, had lost almost every trace of lime and of magnesia, so that it is probable that the greater part of those substances were held in the state of carbonates, by excess of carbonic acid. The carbonate of lime forms films during boiling, which subside, and appear under the microscope in the form of very minute acicular crystals. The crystalline deposit obtained by slowly evaporating the water after the precipitated carbonate of lime has been separated by filtration, exhibits, under the microscope, three distinct forms ; namely, cubes, (of chloride of sodium); prisms, which lie distinct upon the other salts, and are 
efflorescent, (sulphate of soda); and small aggregates of rhomboids intermixed with small spherical particles, like pin-heads, (carbonate of soda). The residue of the evaporation of the water, after having been gradually raised to a dull red heat, acquired a girey tint, and exhaled a slight odour of burning azotized matter; and a piece of moistened turmeric paper held in the evolved vapour was transitorily reddened.

I have not been able to detect any potassa in this water; and only a slight indication of the presence of a phosphate, in the precipitate deposited by the water during boiling.

Upon the whole, I am inclined to regard the following as a tolerably correct statement of the proximate saline components of this water :

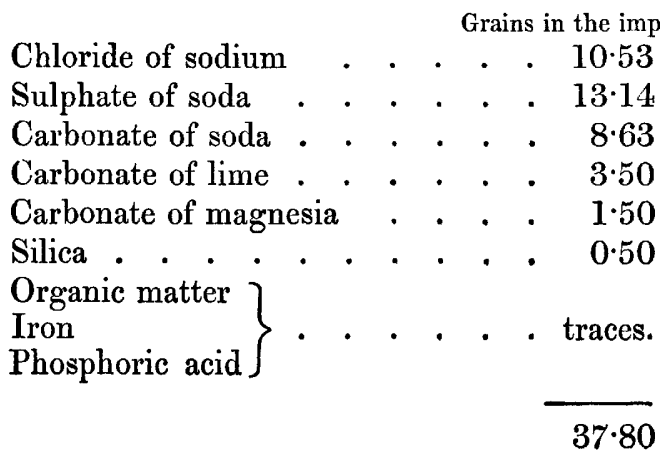

The specific gravity of the water at $55^{0}$ is 10007 . Its gaseous contents I have not ascertained.

A section of the well accompanies this paper, which will shew such details of its construction as I have not thought it necessary to enter into, as well as the relative thickness and position of the intersected strata.

I have examined the water of several other wells in and about London, some of which derive their supplies from the sands under the blue clay, and others, to a greater or less extent, also from borings. into the chalk, and I think that in most cases, the latter waters are the more pure; that is, that in proportion as the borings are deepened into the chalk, the less are the solid contents of the water. There are in London and its vicinity, some very deep wells which yet do not reach the chalk; and others, of a less depth, which are carried into it: arising out of inequalities in the surface of the chalk, and the varying thickness of the blue clay itself; so that the 
variations in the relative quantity of solid matter in the waters derived from these wells, is no criterion of their respective depths.*

The shallow wells of the London district, by which I mean those which do not penetrate the blue clay, but derive their supplies from the gravels and sands above it, yield water of varying quality, but always much less pure than that of the deeper wells, and generally abounding in sulphate of lime, and consequently eminently hard, as respects the decomposition of soap, and other common.culinary uses. There are many of these wells in which analysis detects indications of contamination by sewers, and by the vicinity of gas-pipes; and some of them have been disused and filled up on that account. There are also, as is well known, many which are either in churchyards, or upon their boundaries; and it is from these parish pumps, that the neighbourhood often exclusively derive their supply of drinking-water. I am at present examining the waters of several of these wells. In those which I have already examined, I have been struck with the abundance of nitrates, generally nitrate of lime; and this, in some of them is accompanied by what may be termed a large proportion of organic matter; so large indeed, that on proceeding in one case to heat the dry residue of the water to redness, a deflagration ensued; and yet, this water is bright and colourless, has no unpleasant taste, and is abundantly resorted to as very superior spring-water by a very populous neighbourhood.

How far such waters may or may not be salubrious, is not a question here to be discussed; but in some cases there can, I suppose, be no doubt upon the subject, inasmuch as I have found two of these waters of an evident, though slight, brown or peaty tinge, as furnished from the well; soon becoming brown on evaporation, and yielding abundant evidence of containing that species of humic extractive in which the adjacent soil no doubt abounds. I have in no instance been able to detect ammoniacal salts in any of these waters, but I presume that the nitric acid which they contain is the result of the oxidizement of ammonia.

It was my wish to have laid some of the results of these analyses more in detail, before the Society; my apology for such imperfect details is, the hope that they may engage the attention of other analysts; that the important subject of the condition of the waters of London and its vicinity may meet with the attention it deserves;

* The chief peculiarity of these waters is derived from the presence of carbonate of soda, which notwithstanding the large relative proportion of other salts which they often contain, confers upon them a peculiar softness as regards the soap-test, and seems to render them well adapted for domestic use, and especially for the infusion of tea and coffee. 
and that the comprehensive subject of the metropolitan supply of water may be scientifically, and accurately, and dispassionately considered, by those who are adequate to the task.

As regards the leading question of River supplies on the one hand, and Artesian supplies on the other, I cannot however, help expressing myself decidedly in favour of the former. Deep wells are pre-eminently valuable for local uses; but, the peculiarities of the waters which they afford; the depth from which, in many situations and under most circumstances, those waters must be raised; the possibility, and I think I may say, probability of the inadequacy of their supply; and the chances of their mutual interference, are some of the circumstances which in my mind should be well weighed, before the gigantic scheme of the supply of the metropolis from such sources is seriously entertained. On the other hand, pure River-water is already upon the surface, in various quarters, in unlimited quantity, and at no great distance; and when filtered, an operation which, as experience has shewn, is attainable to any extent, its quality is in all respects superior. That many parts of London are badly and inefficiently supplied with water, and that in some places none is laid on, cannot be denied; but a slight movement in a proper direction, would I think remedy all real evils under this head. I must further beg leave to express my opinion in favour of the adequacy of the existing Water Companies to the accomplishment of all that can be reasonably required : the magnitude of their united means, the general excellence of their arrangements, the practical skill with which they have been devised and executed, and the resources which are still open to them where increase of supply is demanded, are the circumstances upon which I found this opinion.

I shall conclude with a short comparative table, showing the relative quantity of solid matter contained in such river and spring waters as have been carefully analysed; intending, upon a future occasion, to extend the list, to give the details of the analyses, and the names of the analysts ; in their present imperfect state, however, the following details will serve to illustrate some of the points touched upon in the preceding notice. The wells which are termed deep, derive their water from the strata below the blue clay, and some of them penetrate into the chalk; those termed shallow, are supplied from the strata above the blue clay. This is the case with most of the common London wells, which, however, are often steined to a considerable depth in the clay, for the purpose of forming a reservoir. 
Solid matter in the imperial gallon.

Thames at Greenwich . $27 \cdot 9$

$"$ London . . . . . . . . . . $28 \cdot 0$

"Westminster . . . . . . . 24.4

" Brentford • . • • • • • • • • 19.2

" Twickenham . . . . . . . . 224

"Teddington . . . . . . . 1744

Average of the Thames between Teddington and Greenwich . $23 \cdot 2$

New River

Colne

Lea .

Ravensborne at Deptford

Combe and Delafield's Brewery, Long Acre. Deep well . 56.8 Apothecaries Hall, Blackfriars . . . ditto. . . 45.0 Notting Hill . . . . . . ditto. . . $60 \cdot 6$ Royal Mint.$\quad$. $\quad . \quad$. . $\quad$. ditto. . . $37 \cdot 8$ Hampstead Waterworks . . . . ditto. . . 400

Berkeley Square . . . . . ditto. . . 600 Tilbury Fort . . . . . . ditto. . . 75.0

Goding's Brewery, (Lambeth) . . . ditto. . . $50 \cdot 0$ Ditto . . . . . . shallow well . 1100 More's Brewery (Old Street) . . deep well . $38 \cdot 0$ Ditto . . . . . . shallow well . 110.0 Trafalgar Square Fountains $\quad . \quad$. $\quad$ deep well $\quad \cdot 68.9$ Well in St. Paul's Churchyard . . . . . . . 75.0 " Breams Buildings . . . . . . . 1150 " St. Giles, Holborn . . . . . . . . . . $105 \cdot 0$ „ St. Martin's, Charing Cross . . . . . 95.0

" Postern Row, Tower . . . . . . . . . . 88.0 Artesian well at Grenelle, near Paris 9.86 